\title{
SCHMITT PARA LAS IZQUIERDAS: NOTAS SOBRE MARXISMO Y POLÍTICA
}

\author{
Martín Cortés ${ }^{1}$
}

\begin{abstract}
Resumen: El texto propone un recorrido sucinto por los modos en que las lecturas marxistas de fines de los años setenta del siglo XX se apropiaron de la figura de Carl Schmitt, con el propósito de enriquecer con su concepción fuerte de lo político lo que era considerado una debilidad propia del marxismo: su teoría política. Se toman dos casos paradigmáticos en materia de articulación entre Schmitt y Marx: el del italiano Mario Tronti y el del argentino José María Aricó. La lectura parte de la hipótesis de que los ejercicios de Tronti y Aricó se pueden leer como intentos de complementar a Marx con las contribuciones de Schmitt, razón por la cual permanecen al interior del marxismo como horizonte problemático. Finalmente, sugerimos que sobre todo a partir de los años ochenta, y con mayor énfasis de los noventa hacia el presente, las lecturas de Schmitt que continuaron formulándose desde el campo de las izquierdas se hicieron por fuera -y quizá en contra- del marxismo, en la medida en que se lo considera incapaz de producir una teoría compleja de lo político. Se abre entonces la pregunta por los alcances de estas distintas operaciones en materia de crítica del presente.
\end{abstract}

Palabras Clave: Marxismo. Carl Schmitt. Teoría política. Mario Tronti. José Aricó.

A propósito de los modos en que la teoría marxista se corrige volviendo sobre sus pasos, Louis Althusser acudía a la metáfora, tomada de Lenin, de la curvatura del bastón: para corregir una desviación, se procede mediante la fuerza, pero con una fuerza necesariamente excesiva, que tiene por consecuencia una desviación en el sentido contrario. A la curvatura del bastón, le sucede una contracurvatura, y así sucesivamente. Contra el filón del marxismo que se pensaba a sí mismo como filosofía positiva de la historia y consideraba el

\footnotetext{
${ }^{1}$ Profesor en la Carrera de Ciencia Política y en el Doctorado en Ciencias Sociales, ambas de la Facultad de Ciencias Sociales de la Universidad de Buenos Aires (UBA), Buenos Aires - Argentina.

(D) https://orcid.org/0000-0002-3338-5133 E-mail: martincort@gmail.com

Doctor en Ciencias Sociales y Filosofía (Universidad de Buenos Aires - Université Paris 8). Investigador Adjunto del CONICET, con sede en la Universidad Nacional de General Sarmiento. Ha publicado diversos libros y artículos sobre teoría política, teoría del Estado y marxismo latinoamericano.
}

http://dx.doi.org/10.1590/0101-3173.2019.v42n2.08.p151 
desarrollo de la teoría como un continuum acumulativo y verdadero, Althusser se sublevaba excluyendo a Marx de la tradición racionalista. Esto significa que la teoría avanza no por virtud de iluminar la realidad con su verdad, sino como efecto de relaciones de fuerza:

No podemos contentarnos con predicar lo verdadero en su total desnudez y esperar que su evidencia anatómica 'ilumine', como decían nuestros ancestros del siglo XVIII, los espíritus: estamos realmente forzados, ya que se trata de forzar las ideas para que cambien, a reconocer la fuerza que las mantiene en estado de curvatura, imponiéndoles, por una contrafuerza que anula la primera, la contracurva que es precisa para enderezarlas. (ALTHUSSER, 2008, p. 218).

De esta manera, toda la historia de la teoría transcurre de desviación en desviación (y así explica Althusser su excesivo teoricismo para discutir con el excesivo espontaneísmo del marxismo humanista). Con todo esto se construye una notable paradoja: se niega la existencia de una línea verdadera por la cual el marxismo discurre, al tiempo que se señala que este discurrir sucede como si estuviera buscando permanentemente esa línea. A esto llama Althusser error sin verdad o desviación sin norma: fórmulas aparentemente paradojales que caracterizan su marxismo, pero que son, en realidad, signos de una filosofía materialista que se sabe siempre excedida por un real que no domina.

Bajo este prisma podríamos intentar leer el encuentro entre el marxismo y Carl Schmitt (dicho con mayor amplitud, entre las izquierdas y Carl Schmitt): como la fuerza de lo político que viene a oponerse a consolidadas desviaciones economicistas. En esa dirección, sin pretender hacer una historia de las lecturas que cruzaron ambos horizontes, y tampoco intentando ser justos con aquello que efectivamente dice Schmitt, nuestra intención es mostrar de qué modo su bagaje teórico operó, en algunas apropiaciones marxistas de su obra, para expandir y profundizar la pregunta por lo político.

Aunque se podrían encontrar ya en los ańos treinta lecturas contemporáneas de Schmitt desde el universo marxista (tal es el conocido caso de Walter Benjamin), el fenómeno de incorporación de sus reflexiones a los debates de izquierda se inicia con más fuerza en los años setenta. Esto tiene que ver, fundamentalmente, con la llamada "crisis del marxismo". No cabe entrar aquí en detalle en las implicancias de esto, nos basta señalar que con ese nombre, demasiado amplio, se puede aludir a la multiplicación de lecturas posibles del legado de Marx, que se abren con el quiebre de la hegemonía 
del marxismo soviético como ideología oficial de las izquierdas del mundo. Se suele situar esta divisoria en la década del cincuenta, con la muerte de Stalin en 1953, la desestalinización que anima el XX congreso del PCUS en 1956 y la consiguiente apertura de los debates teóricos en muchos partidos comunistas de Occidente. Los sesenta multiplicarían las lecturas divergentes de Marx, cada vez más incorporado en las más diversas corrientes de las ciencias humanas en general. Para llegar a los setenta con un marxismo que, a fuerza de derrotas y encerronas políticas, ya no puede eludir la radical puesta en cuestión de algunas de sus grandes coordenadas filosóficas. La llamada "crisis del marxismo" aparecería con ese nombre propio fundamentalmente en Italia, que será también el país donde la apropiación de Schmitt por parte de las izquierdas constituirá un fenómeno teórico de gran alcance.-

¿Por qué Schmitt? La principal característica del marxismo que estallaba con la crisis era la presencia, a modo de sustrato último que se había ido consolidando como fondo de la doctrina oficial, de una filosofía de la historia que otorgaba las garantías precisas para leer el devenir como un camino inexorable hacia el socialismo. Y aquí la noción de progreso subyacente no es lo más grave, sino la presencia de una tesis simplificadora de lo social: en el desarrollo técnico se cifraba el sentido de la historia, y a ello se reducían, más o menos mediadamente, los distintos problemas de la vida de las sociedades. Hay que decir, con firmeza, que este era el estado real y mayoritario, al menos hasta los años sesenta, de aquello que había tomado el nombre de marxismo mucho más que el legado múltiple de la fenomenal obra de Marx (aunque no se trata, tampoco aquí, de hablar de fidelidades o lecturas justas e injustas $)^{2}$. Y que, por cierto, figuras como los mencionados Benjamin y Althusser ya habían hecho bastante por mostrar otras vías posibles de lectura pero, en cualquier caso, este marxismo tenía por evidente consecuencia la convicción de que todo cuanto sucedía en el orden político encontraba su razón y explicación última en otro lugar.

\footnotetext{
2 Se han hecho múltiples trabajos en torno del problema de la política en Marx, señalando los diversos modos en que éste la tematiza. A los fines de los problemas que se discuten en este trabajo, podemos remitir al texto de Etienne Balibar (1980) "Estado, partido, ideología: esbozo de un problema". Allí se da cuenta de dos grandes modos de comprensión de la política en Marx. Una, regida por un normativismo que de algún modo reenvía a Hegel, coloca a la política como efecto de las relaciones de producción, a partir de lo cual sólo busca en estas últimas la determinación que resultaría en la forma que la política debería asumir. La otra, más productiva para Balibar -y para nosotros-, implica concebir a la política a partir del análisis histórico, revisando así los modos específicos de su vinculación con las relaciones de producción y con la totalidad. De allí que la lucha ideológica y la lucha política reclamen un tratamiento específico, no inmediatamente reductible a las condiciones económicas. Es justamente en este hiato que aparece, para algunos autores que aquí revisamos, la necesidad de acudir a Carl Schmitt.
} 
La técnica como neutralización, la política como derivación de la economía: la convocatoria a Schmitt parece imponerse fácilmente. Y sobresale otro elemento, epocal, que explica el éxito de la operación de lectura del jurista alemán desde el marxismo: la creciente relevancia del problema del Estado. Ya desde los sesenta, cuando se inicia el intercambio entre Ralph Miliband y Nikos Poulantzas en las páginas de la New Left Review ${ }^{3}$, los debates marxistas sobre el Estado crecían en importancia y complejidad. En los setenta se generalizan y toman, con el estallido de la crisis del marxismo, el nombre de la indagación por la teoría política del socialismo. Figuras tan disímiles como Norberto Bobbio y Louis Althusser coincidían en el diagnóstico: la carencia de tal teoría en el horizonte marxista. Las consecuencias eran antagónicas, para el italiano eso equivalía a un juicio normativo que daba por asegurado el deslizamiento autoritario de todo intento por plantear la transformación socialista; para el francés era una oportunidad para recordar que el marxismo era una teoría crítica y no una filosofía positiva, razón por la cual no podía ofrecer una teoría positiva del Estado socialista en oposición a la crítica del Estado capitalista 4 . En cualquier caso, desde vías muy divergentes, en el clima general de la época asomaba la búsqueda de los elementos conceptuales que permitieran trabajar sobre la complejidad de lo político sin reducirlo a la determinación económica. Y allí la problematización de la cuestión del Estado no era antojadiza, sino dictada por las décadas de desarrollo de las mediaciones estatales bienestaristas, que hacían cada vez mayor la necesidad de complejizar las herramientas de análisis de la dimensión política de las relaciones sociales capitalistas. Esta cuestión, además, excedía el plano analítico y teórico, y se situaba directamente a nivel estratégico: ¿Cómo pensar la relación entre revolución y Estado cuando la tesis clásica de la extinción ya no puede dictar las tácticas a seguir? ¿Qué relación puede establecerse entre transformación social y legalidad? Y, con esta última: ¿Qué rupturas y continuidades operan entre la democracia burguesa y la democracia socialista?

\footnotetext{
3 De este debate emergen algunos de los textos más importantes en materia de teoría marxista del Estado, entre ellos Poder politico y clases sociales en el Estado capitalista (1968) y Estado, poder y socialismo (1978) de Poulantzas; y El Estado en la sociedad capitalista (1968) y Marxismo y politica (1977), de Miliband. Una mirada general de las alternativas del debate puede consultarse en Tarcus (1991)

${ }^{4}$ Las posiciones de Althusser y de Bobbio en esta materia, y la de muchos otros importantes marxistas franceses e italianos, ha sido publicada en castellano, en 1982, por José Aricó en el volumen Discutir el Estado. Posiciones frente a una tesis de Louis Althusser (traducción de la compilación italiana de 1978). El libro es parte de la colección "El tiempo de la política", que Aricó dirigía en la Editorial Folios en México y que, como veremos más abajo, publicará también El concepto de lo político de Carl Schmitt.
} 
Estos dilemas no sólo convocan a Schmitt como contribución teórica, sino que hay que señalar que él mismo fue consciente de ellos. Por eso podemos encontrar sus indagaciones, en aquellos mismos años, en torno del plus de poder político que la legalidad entrañaba: en La revolución legal mundial, de 1978, se detiene nada menos que en la figura del líder comunista español Santiago Carrillo, quien junto a sus pares de Francia e Italia (Georges Marchais y Enrico Berlinguer), postulaba la vía legal como signo de la estrategia de transformación social en los países desarrollados de Europa, el llamado "eurocomunismo" (SCHMITT, 2012). Y es precisamente en el marco de estos debates sobre la política y el Estado que la figura de Schmitt asoma al horizonte marxista y, al mismo tiempo, al horizonte de las izquierdas en general. En lo que sigue, señalaremos brevemente algunas variantes de estos modos de recepción del jurista alemán, para cerrar con algunas hipótesis sobre los dilemas teórico-políticos contemporáneos que dejan estas conjunciones.

\section{SCHMitT COMO COMPLEMENTO: DOS CASOS}

Italia fue escenario pionero y fundamental de la apropiación de izquierdas del pensamiento de Schmitt. En 1972 se publica en Bolonia La categorie del 'político', conjunto de textos que incluye entre otros El concepto de lo político. Si bien tarda unos ańos la incorporación generalizada de sus reflexiones a los debates teóricos marxistas (esto se verá con claridad al final de la década), es evidente la afinidad de sentido entre sus propuestas y los temas que circulan crecientemente en publicaciones y revistas de la época. Tomemos el caso del importante libro de Mario Tronti, Sull'autonomia del político, edición de 1977 que contiene dos intervenciones, una de 1972, apenas meses posterior a la mencionada publicación de Schmitt, otra de 1976. Aunque la presencia del alemán es mucho más a través de sus conceptos que de referencias directas, a la luz de comentaristas posteriores, el texto es tomado casi con unanimidad como pionero en el ejercicio de combinación de Schmitt y Marx 5 .

\footnotetext{
${ }^{5}$ En una entrevista reciente que hemos realizado a Mario Tronti en la ciudad de Roma (febrero de 2016), él mismo afirmó que en Sull'autonomia del político su conocimiento de Schmitt era "intuitivo". Para encontrar sus primeros trabajos sistemáticos sobre el tema debemos avanzar algunos ańos, al menos hasta su participación en el Coloquio "La política oltre lo stato: Carl Schmitt", organizado por el Istituto Gramsci Veneto en 1980 y publicado un año después (TRONTI, 1981). Camino que profundizaría en su participación, entre 1981 y 1983 en la revista Laboratorio político y que de algún modo estará presente a lo largo de su itinerario intelectual, en sus múltiples ensayos de utilización revolucionaria de la teoría política conservadora.
} 
Como señala el propio Tronti en una pequeña semblanza autobiográfica (TRONTI, 2012), las reflexiones sobre la autonomía de lo político deben enlazarse a los efectos del período operaista que él y otros jóvenes del comunismo y el socialismo italiano habían atravesado en los años sesenta. En ese período reivindicaron un análisis científico del desarrollo de la clase obrera y su centralidad en las luchas políticas, contra la tradición historicista gramsciana del Partido Comunista Italiano, siempre proclive a subrayar la singularidad y el atraso italiano, y con ellos, la preminencia de un bloque popular por sobre la noción de clase. En la capacidad del sistema de reconfigurarse políticamente para contener aquellas luchas se cifra la necesidad de una compleja teorización sobre lo político. Al mismo tiempo, la reflexión sobre la autonomía de lo político supone una crítica de las limitaciones de los movimientos del 68: la lógica de la insurrección societal, desde abajo, mostraba sus limitaciones en una naciente ideología del capitalismo neoliberal que tomaba para sí sus banderas libertarias en contra del Estado social. Hacía falta una fuerza política organizada, y esto era así porque el conflicto estaba colocado en el orden de lo político, las luchas obreras excedían el plano económico y teñían la reconfiguración política del capitalismo. Entonces aparece Schmitt. Según recuerda Tronti en su "Karl und Carl" de 1998, la ambición era la de "arrancar a Schmitt el secreto de la autonomía de lo político para recolocarlo, como arma, en el partido de la clase obrera" (TRONTI, 1998, p. 159) , para comprender el sentido de la política como potencia originaria, y no como efecto de la economía.

Lo que sobresale rápidamente en Sull'autonomia del político es la necesidad metodológica de Schmitt. Esto es así porque la presunción de autosuficiencia de la economía para explicar las crisis y las luchas está puesta en cuestión por la propia realidad. La principal hipótesis de Tronti, en este punto, es que existe un ciclo político del capital irreductible a su ciclo económico. Dicho en otros términos, que existe una autonomía del poder respecto de lo que se supone es su fundamento (con lo cual la idea misma de la economía como fundamento del poder está puesta en cuestión). La especificidad del ciclo político implica entonces la existencia de diversas temporalidades, más precisamente, de un retraso de lo político. Ahora bien, este retraso no deriva, para Tronti, de una falta de desarrollo, sino que es constitutivo de la máquina estatal. Ésta, en la medida en que se desarrolla el gran capitalismo, muestra un diverso ritmo de racionalización, una productividad y una

\footnotetext{
${ }^{6}$ En esta citación, y en todas las sucesivas que lo requieran, la traducción del italiano al español es nuestra.
} 
eficiencia indudablemente defectuosas en relación con el ciclo económico (de allí que pueda hablarse de la historia del capital como una doble historia: continuidad económica y discontinuidad o salto político). Es precisamente en ese funcionamiento aparentemente defectuoso que el Estado absorbe las contradicciones económicas e impide su explosión, pudiendo así controlar la crisis. La contradicción se sitúa, de este modo, directamente en el plano político, de allí su autonomía como problema teórico, y estratégico.

Queda entonces criticada fuertemente cualquier tesis de determinación y sincronía entre estructura y superestructura, y en su lugar encontramos casi un programa de investigación: es preciso pensar la historia del capital y del Estado como dos historias paralelas (aunque Tronti nos hable del capital y su Estado). El Estado es una necesidad creciente del capital (mucho más en el siglo XX que en el XIX) como condición de posibilidad de su dominio, pero lo es bajo sus propias formas y leyes. Estas historias paralelas, a la vez, no son historias de dos aspectos pacíficamente complementarios, sino en tensión permanente. De modo que pueden tomar la forma de la lucha entre el capital y su Estado. Si las temporalidades de la economía y la política son divergentes, nos dice Tronti, puede también suceder que una se vuelva contra la otra.

Aquí aparece la doble apuesta, filosófica y política: en el primer caso, romper con todo organicismo historicista que postule la unidad del despliegue histórico (otro signo del antigramscismo de Tronti). Políticamente, se juega aquí la posibilidad de radicalizar la plena politización del antagonismo de clase: la economía como categoría del capital, la política como categoría de la clase obrera. Nos dice Tronti: "El Estado moderno resulta, en este punto, nada menos que la moderna forma de organización autónoma de la clase obrera." (TRONTI, 1977, p. 20). Esto es así porque la situación de crisis del capitalismo requiere una transformación política, y esa transformación será una revolución conservadora o será la vía por la cual la clase asuma la centralidad política. En este punto hay una suerte de gran oportunidad histórica: para Tronti las luchas, épicas y heroicas, que la clase ha llevado adelante en el nivel económico nunca la han sustraído de su condición de subalterna. Con la lucha al nivel político se abre la ventana para la ruptura del ciclo del capital.

Se trata de una lucha, entonces, de la política contra la economía (y contra la historia). La separación de estos dos ciclos nunca es sólo una distinción, sino el dominio de uno sobre otro. La historia del capital es la historia del dominio de la economía, la posibilidad de la clase obrera es la del dominio de la política. Ahora bien, y aquí Tronti se aproxima decididamente a los significantes schmittianos: 
no existe garantía histórica ni de ningún tipo que ordene esta confrontación. La posibilidad de subversión de la relación entre economía y política es descrita de este sugerente modo por nuestro autor: "La subversión [rovesciamento] no está ligada a un proceso objetivo de la crisis capitalista, tampoco a los términos políticos de esta crisis. La instancia de esta subversión puede ser solamente llevada adelante subjetivamente, decisionalmente" y el mismo Tronti aclara: “(para usar términos provocativos)” (TRONTI, 1977, p. 76).

Pasemos rápidamente a otra operación de apropiación de Schmitt, más conocida para los lectores latinoamericanos, y más explícita que la de Tronti: la edición de El concepto de lo político que José Aricó realiza en la colección "El tiempo de la política" (mismo título que llevaba el libro publicado en 1980 por, justamente, Mario Tronti), que dirigía en la editorial Folios. El libro, publicado en México y en Argentina en 1984, se inscribe en una larga estela de reflexiones e intervenciones de Aricó (ya sea como textos propios o como ediciones $)^{7}$ en torno de la cuestión de la teoría política del socialismo -que ya hemos mencionado que era central en los debates de la crisis del marxismo-. Estas, desplegadas fundamentalmente en el contexto de su exilio en México, que buscaban debatir con los modos en que el marxismo fue consolidándose como una filosofía de la historia, que implicaba tanto una doctrina del progreso como un lugar subalterno para la política, como expresión de algo que se validaba en otro lugar. Para ello Aricó desplegó sus estrategias bibliófilas de indagación en los más diversos rincones de la tradición marxista, mostrando que en ella anidaban formas muy disímiles, y mucho más productivas, de pensar la historia y la política. Su estrategia buscaba además enlazar al marxismo con las más diversas corrientes teóricas y culturales que pudieran auxiliarlo en esta búsqueda. Y allí aparece, junto a figuras como Weber y Kelsen, Schmitt.

En la presentación del texto ${ }^{8}$, Aricó establece rápidamente lo que podemos identificar como las dos razones para buscar en Schmitt un encuentro original con Marx. En primer lugar, para sustraer al marxismo

\footnotetext{
7 Para un mapa de la tarea editorial y los textos de Aricó en torno del problema de la teoría política del marxismo, centrado especialmente en la experiencia de la editorial Folios ver Cortés (2014).

${ }^{8}$ Cabe subrayar la importancia contextual de este texto, ya que su propósito, además de analizar teóricamente las contribuciones de Schmitt, es el de explicar el sentido de publicar a este controvertido autor en el sensible clima político-intelectual de los años ochenta. En el caso argentino, apenas un año antes había concluido la dictadura, y además el liberalismo político era cada vez más hegemónico en el campo cultural, dejando atrás los tiempos de dominio del marxismo. En ese contexto, como muestra Jorge Dotti (2000), la publicación de Aricó estuvo lejos de producir el efecto buscado: antes que permitir discutir con las lecturas lineales o pobres de Marx, fue poco atendido porque el clima liberal se presentó incompatible con la propuesta de lectura de Schmitt.
} 
del par racionalismo/irracionalismo en que las tesis del Lukács del Asalto a la razón lo habían encerrado. Según esta lectura, el marxismo "no indicaba la tentativa más radical de crítica de un mundo al que la crisis tornaba siempre más indecible, sino la consumación de las concepciones racionalistas que el cosmos burgués elevó a su máxima expresión" (ARICÓ, 1984, p. X). De este modo no sólo se lo identificaba con la lógica del progreso, sino que se le negaba la posibilidad de alimentarse de las potentes críticas de la modernidad que, entre otros, aporta Schmitt en los tiempos de la crisis de entreguerras. Y se olvidaba, a la vez, que la crítica de Marx tiene necesariamente una dimensión destructiva, que nos obliga a rescatar (y nótese la fuerza de la expresión, que bien podríamos llamar irracionalista): "La demoníaca voluntad puesta de manifiesto [por Marx] en su deconstrucción de la Economía política como verdadera 'ciencia' del poder de su época." (ARICÓ, 1984, p. XI).

Aquí aparece la segunda razón: destacar la politicidad de la obra de Marx. Para ello, Aricó precisa distinguir a Marx de sus seguidores (a quienes llama, en realidad, "epígonos"), quienes no habrían entendido esa dimensión intensamente política de la crítica marxiana. Es entonces cuando acude a Schmitt: si bien sería demasiado considerarlo un "proseguidor" de Marx (aunque Aricó termina por sugerir eso), existe un horizonte común: "Aun con propósitos radicalmente opuestos a los suyos, Schmitt se sitúa en el pleno reconocimiento de lo que para nosotros caracteriza la contribución epocal que Marx produjo: la determinación esencialmente política de la economía." (ARICÓ, 1984, p. XI). Así, la interpelación hecha a través de esta controvertida figura apunta a criticar el economicismo y, sobre todo, la aceptación de una escisión tajante entre política y economía que permite pensar el proceso económico como una forma de lo técnico, y no como un espacio conflictivo, es decir, constitutivamente político, aun cuando aparezca neutralizado por el discurso de la ciencia económica. Este punto que, según Aricó, reúne a ambos autores alemanes, no siempre habría sido tenido en cuenta por las izquierdas. No es tan relevante si, como afirma Schmitt, Marx efectivamente hace empatía con el relato ilustrado de la pujante burguesía, como dar cuenta críticamente de las lecturas que han insistido en situar y retener al marxismo en el terreno económico. En esos casos, la crítica de la política sólo podía ser pensada como "emanación directa de la crítica de la economía política” (ARICÓ, 1984, p. XII).

Al igual que con Tronti, la búsqueda de una reflexión política desenlazada de la normatividad y lista para afrontar tiempos de grandes transformaciones en el lugar del Estado y en los modos de ejercicio de lo político, son dos 
elementos cruciales en el ensayo de lectura de Schmitt que despliega Aricó. Este ensayo buscaba poner al marxismo a la altura de su crisis, para lo cual se precisaba desligarlo de las garantías que la filosofía de la historia le otorgaba. Y permitirle en su lugar confrontarse con un mundo de conflictos expandidos e irreductibles a una sede privilegiada (sea el Estado o el partido, dice Aricó). De modo que la hipótesis de la transformación social queda, como en Tronti, más cerca del decisionismo que de la racionalidad histórica.

Las perspectivas de Tronti y Aricó podrían leerse como experimentos de complementariedad entre Marx y Schmitt. Por carencias teóricas efectivas -ya sea que surjan del pensamiento de Marx o del modo en que su tradición se consolidó-, y por necesidades propias de cambios epocales, el pensamiento fuerte de lo político de Schmitt venía a encontrarse con un legado demasiado orientado a la reflexión sobre lo económico-social. Es en este sentido que podemos volver a la metáfora del bastón con que iniciamos el texto. Si la curvatura se inclinaba hacia un plano economicista, Schmitt funciona como el golpe que nos envía a la contracurvatura, la de lo político irreductible, autónomo. Ahora bien, la complementariedad no supone aquí una mera adición o yuxtaposición de dos elementos, sino el esfuerzo por la producción de una estrategia teórico-política novedosa, que en cierto sentido desarma la tradicional contraposición entre economía y política, para darnos en su lugar una idea de prácticas diferenciadas pero a la vez estrechamente relacionadas?

¿Todo es político?

Incorporando a Schmitt, los ensayos de "complementación” de Tronti y Aricó se reconocen interiores a la tradición marxista. A ellos le sucedieron nuevos y diversos modos de incorporar a Schmitt cada vez menos interesados por la lógica de lo complementario, para colocar en su lugar una lectura del jurista alemán que abonaba a la denegación de los grandes fundamentos del legado marxiano. No podríamos resumir aquí la abundante bibliografía que recorrió estos caminos, sino apenas mencionar algunos de sus nudos más salientes. Quizá una de las apropiaciones más exitosas -al menos en términos de difusión- de Schmitt para un pensamiento de izquierda haya sido el que proviene de la lectura de Ernesto Laclau y, mucho más aun, de Chantal Mouffe.

9 En el caso específico de Aricó, esta preocupación acompaña buena parte de sus textos de la época. Entre los cuales podemos subrayar su curso de 1977, Nueve Lecciones de economía y política en el marxismo, que constituye un denodado esfuerzo por construir una lectura de la tradición marxista que rescate a los exponentes que supieron elaborar una teoría compleja y no reduccionista de la relación entre economía y política (ARICÓ, 2011). 
Los colocamos juntos porque de algún modo es su clásico Hegemonía $y$ estrategia socialista, de 1985 , el que establece un horizonte de crítica del marxismo que abre las puertas para recibir el influjo schmittiano (y en eso será efectivamente Mouffe mucho más insistente que Laclau). A contramano de lo que señalaba Aricó, esa crítica consistía en colocar al marxismo en la vía de un racionalismo organizado en torno de una esencia social última, de modo que toda política, por más compleja que sea, pueda reducirse a un núcleo racional situado al nivel de las clases sociales (LACLAU; MOUFFE, 2004). En su libro El retorno de lo político (MOUFFE, 1999, p. 36), Mouffe caracteriza rápidamente al marxismo ( $\mathrm{y}$ al liberalismo, que funciona como su otro complementario) como una doctrina de la reconciliación y el dominio. Por ello, señala, puede resultar paradójico que algunas corrientes del pensamiento conservador sean más útiles para el mentado retorno de lo político que las viejas tradiciones ilustradas que contienen, entre otros, al marxismo. Schmitt ha sido, pues, convocado, pero no ya para complementar a Marx, sino para producir una teoría política más allá de él. Teoría que, bajo la forma de la lucha por la democracia radical, descansa en los antagonismos contingentes que se definen siempre en el orden de lo político-discursivo, sin que ninguna dimensión estructural preserve el derecho a una legitimidad especial.

La autonomía de lo político ya no es aquí una crítica de la topología clásica marxista y las rígidas determinaciones que de ella emanaban, sino la expansión de lo político como lógica que atraviesa la totalidad o, más bien, que da cuenta de la imposibilidad de la totalidad como cierre. Con esta apropiación de Schmitt lo político ya no está en ningún lugar sino en todos, y es su forma singular la que hace inteligible, siempre parcialmente y en movimiento, los conflictos que atraviesan la sociedad.

Todo es político: la contracurvatura del bastón pareciera estar aquí en el lado más lejano de aquel economicismo marxista que el auxilio de Schmitt ayudó a conjurar. Cabría preguntarse si no necesitamos entonces un nuevo golpe que nos entregue algunas claves de lectura que nuestro presente reclama. Todo movimiento del bastón deja algunas enseñanzas: hoy es imposible restituir la infalibilidad de lo económico o pretender que la política no está allí. Pero, también arrasar los restos topológicos del marxismo puede traer consigo el borramiento de las diferentes temporalidades, y de la especificidad de las prácticas, que componen toda coyuntura. Que la economía sea también política no implica que no tenga su lenguaje específico, su temporalidad específica, en cierto sentido irreductible a la vez a la verdad política que la 
constituye. La precaución es frente a los modos de expansión de lo político, muy presentes en la teoría política contemporánea, que necesitan a su vez de una simplificación de "lo económico-social", para decir que se trata de un resto esencialista o, en el mejor de los casos, un antagonismo más en la larga serie gobernada por el lenguaje de lo político.

Allí preguntaríamos, con Žižek (2003), si esa crítica demoledora de la universalidad marxista no entrañó un sacrificio demasiado apresurado de la pregunta por las grandes lógicas de ordenamiento de la dominación. Vale decir, si el repudio a la lucha de clases como fundamento último, y la rápida asociación entre totalidad y totalitarismo, no implicaron una igualación de las contradicciones (no en su valor específico, sino en la contingencia de asumir el lugar privilegiado de la hegemonía) que nos dificultó el análisis de las profundas transformaciones del capitalismo neoliberal. Transformaciones que implicaron, precisamente, la multiplicación y diversificación de demandas que sin dudas trazan el sentido de las estrategias políticas que las izquierdas deben darse en nuestros días. Pero que, a la vez, no deberían oscurecer el trágico y arrollador mecanismo de dominación que opera en esa temporalidad siempre más lenta y profunda que caracteriza, para decirlo con una noción provocativa y sin dudas ya inaceptable, a la estructura económica.

CORTÉS, M. Schmitt for leftists: notes on Marxism and politics. Trans/form/ação, Marília, v. 42, n. 2, p. 151-164, Abr./Jun., 2019.

\begin{abstract}
This paper proposes a brief tour of the ways in which Marxist readings of the late 1970s appropriated the figure of Carl Schmitt in order to enrich Marxist political theory (which was considered weak) with Schmitt's strong conception of the political. The paper revisits two paradigmatic cases of complementarity between Schmitt and Marx: the Italian Mario Tronti and Argentine Jose Maria Aricó. The paper puts forward the hypothesis that the exercises of Tronti and Aricó are attempts to supplement Marx with contributions from Schmitt, which is why they remain problematic within Marxism. Finally, we suggest that from the 1980s onward, and with greater emphasis since the 1990s, readings of Schmitt made from the left are outside (and perhaps in contradiction with) Marxism, to the extent that they are considered unable to produce a complex theory of the political. The paper ends by discussing the present-day scope of these various critiques.
\end{abstract}

KeYwords: Marxism. Carl Schmitt. Political theory. Mario Tronti. José Aricó. 


\section{REFERENCIAS}

ALTHUSSER, L. Defensa de tesis en la Universidad de Amiens. In: La soledad de Maquiavelo. Madrid: Akal, 2008. p. 209-248.

ARICÓ, J. Presentación. In: SCHMITT, C. El concepto de lo politico. México: Folios, 1984. . Nueve lecciones de economía y politica en el marxismo. México: Colmex, 2011.

BALIBAR, E. Estado, partido, ideología: esbozo de un problema. In:

LUPORINI, C.; TOSEL, A. (org.) Marx y su critica de la política. México: Nuestro Tiempo, 1980. p. 108-169.

CORTÉS, M. El tiempo de la política: la última aventura editorial de José Aricó. Políticas de la Memoria, v. 15, p. 257-267, 2014.

DOTTI, J. Carl Schmitt en la Argentina.Rosario: Homo Sapiens, 2000.

LACLAU, E.; MOUFFE, C. Hegemonía y estrategia socialista: hacia una radicalización de la democracia. Buenos Aires: Fondo de Cultura Económica, 2004.

MOUFFE, C. El retorno de lo político: comunidad, ciudadanía, pluralismo, democracia radical. Barcelona: Paidós, 1999.

SCHMITT, C. La revolución legal mundial. Buenos Aires: Hydra, 2012.

TARCUS, H. Introducción al debate Miliband-Poulantzas. In: MILIBAND, R.; POULANTZAS, N.; LACLAU, E. Debates sobre el Estado Capitalista. Buenos Aires: Imago Mundi, 1991.

TRONTI, M. Sull'autonomia del politico. Milano: Feltrinelli, 1977.

. Marx e Schmitt: un problema storico-teorico. In: DUSO, G. La politica oltre lo stato: Carl Schmitt. Venezia: Arsenale Coperativa, 1981. p. 25-40.

. Karl und Carl. In: TRONTI, M. La politica al tramonto. Torino: Einaudi, 1998. p. 151-164.

Nuestro operaismo. New Left Review, v. 73. p. 102-120, 2012.

ŽIŽEK, S. ¿Lucha de clases o posmodernismo? ¡Sí, por favor! In: BUTLER, J.; LACLAU, E.; ŽIŽEK, S. (org). Contingencia, hegemonía, universalidad. Buenos Aires: Fondo de Cultura Económica, 2003. p. 95-140.

Recebido: 11/04/2016

Aceito: 02/03/2018 
CORTÉS, M. 